\title{
Estimation of Fama and French Model with Augmented Risk Factors: Case of KSE-Pakistan
}

\author{
Syed Asim Shah ${ }^{1}$, Abdul Ghafoor ${ }^{1} \&$ Muhammad Asif Khan ${ }^{1}$ \\ ${ }^{1}$ Faculty of Management Sciences, National University of Modern Languages, Islamabad, Allama Iqbal Open \\ University Islamabad, Pakistan \\ Correspondence: Syed Asim Shah, Faculty of Management Sciences, National University of Modern Languages, \\ Islamabad, Allama Iqbal Open University Islamabad, Pakistan. E-mail: s.asimshah86@yahoo.com
}

Received: February 21, 2014

Accepted: July 24, $2014 \quad$ Online Published: August 22, 2014

doi:10.5539/ijbm.v9n9p161

URL: http://dx.doi.org/10.5539/ijbm.v9n9p161

\begin{abstract}
This paper finds the empirical evidence on the applicability of Fama and French model on Pakistan Stock exchange. The emerging markets have different traits or characteristics as compare to the developed markets. There is lack of evidence that whether the size and book-to-market equity affect the emerging markets or not. The Fama and French took two extreme points to form the portfolios SMB (small minus big) and HML (high minus low), as risk is not static there can be number of numerous factors which effect the stock returns. We will take three points for both factors namely; small, medium and big for SMB and high, medium and low for HML. In addition, wants to see the effect of medium capitalize firms and medium book-to-market firms. The main purpose behind this to address the Pakistan market and find the applicability of fama and french model for the emerging market, along with this find out whether the CAPM, Traditional Fama \& French or Modified Fama \& French provide the more appropriate information for risk return relationship, on monthly data for this purpose. As Iqbal and Brooks (2007) found that daily, data provide more reliable and informative risk return relationship as compare to the monthly and weekly for both beta and for Fama and French factors.
\end{abstract}

Keywords: growth stock, value stock, market to book value, augmented risk factor, portfolio risk, Egarch

\section{Introduction}

Investors who want or looking to invest in stock market has to evaluate the level of risk along with the expected changes in prices. When they buy the security or stock, they are expecting return in future against the money they invested. One should need to consider the factors, which can affect the prices of stocks and the returns.

In 1964 Sharpe, Lintner and Mossion suggested the Capital Assets Pricing Model: CAPM, relationship between single market factor and asset return. In initial years of its models, it was popular and used as a base for other models too. CAPM using single factor to explain the comparison among the excess returns of a portfolio with the excess returns of the market as a whole, in this regard it oversimplifies the market. After some years many financial analysts challenged this model and they debated that market, risk alone cannot capture the whole risk associated with other factors too. So Merton proposed to Multifactor CAPM, a model that will consider the other factors also.

In 1976, Ross proposed Arbitrage Pricing Theory: APT, this law determines the relationship between the asset returns and economy risk factors. This model is sensitive with the economy of respective country and it has problem of defining variables.

In 1992 Fama and French suggested a new model fama and french three factor model. fama and french model used two classes of stocks to explain market's excess return such as SMB and HML respectively. According to the model, expected return on a portfolio in excess of the risk free rate is explained by the sensitivity of its return to three factors; firstly the excess return on the market portfolio, secondly the difference between the return on a portfolio of small firms and on a portfolio of large firms (SMB) and thirdly the difference between the return on a portfolio of high book-to-market equity and the return on a portfolio of low book-to-market equity (HML).

Fama and French started with the observation that two classes of stocks have tended to do better than the market as a whole: (i) small caps and (ii) stocks with a high book-value-to-price ratio (customarily called "value" stocks; 
their opposites are called "growth" stocks). They then added two factors to CAPM to reflect a portfolio's exposure to these two classes:

$$
r-R_{f}=\text { beta }_{3} \times\left(K_{m}-R_{f}\right)+b_{s} \times S M B+b_{v} \times H M L+a l p h a
$$

Here $r$ is the portfolio's return rate, $R_{f}$ is the risk-free return rate, and $K_{m}$ is the return of the whole stock market. The "three factor" beta is analogous to the classical beta but not equal to it, since there are now two additional factors to do some of the work. SMB and HML stand for "small [cap] minus big" and "high [book/price] minus low"; they measure the historic excess returns of small caps and "value" stocks over the market as a whole. By the way SMB and HML are defined, the corresponding coefficients $b_{s}$ and $b_{v}$ take values on a scale of roughly 0 to 1 : $b_{s}=1$ would be a small cap portfolio, $b_{s}=0$ would be large cap, $b_{v}=1$ would be a portfolio with a high book/price ratio, etc (Note 1).

One of three factors in the Fama and French stock pricing model. SMB accounts for the spread in returns between small- and large-sized firms, which is based on the company's market capitalization. This factor is referred to as the small firm effect, as smaller firms tend to outperform large ones as smaller firms are more risky than larger firms. Fama and French's Three Factor model is a way to evaluate a portfolio manager's returns. A typical measure of good performance is large excess returns. The three factors, including SMB, attempt to explain excess returns made by a manager's portfolio. Incorporating SMB shows whether management was relying on the small firm effect (investing in stocks with low market capitalization) to earn an abnormal return. If the manager was buying only small-cap stocks, then his excess return would be diminished compared to if high yielding large stocks were also selected (Note 2).

One of three factors in the Fama and French asset pricing model. HML accounts for the spread in returns between value and growth stocks. HML argues that companies with high book-to-market ratios (value stocks) outperform those with low ones (growth stocks). Also referred to as the "value premium". Fama and French's Three Factor model is often used to evaluate a portfolio manager's returns. A typical measure of good management is large excess returns.

The model's three factors, including HML, attempt to explain excess returns in a manager's portfolio. Specifically, HML shows whether a manager was relying on the value premium (investing in stocks with high book-to-market ratios) to earn an abnormal return. If the manager was buying only value stocks, the model regression would show a positive relation to the HML factor, which explains that the portfolios returns are accredited only to the value premium. Because the model can explain more of the portfolio's return, the original excess return of the manager decreases (Note 3 ).

This paper finds the empirical evidence on the applicability of fama and french model on Pakistan Stock exchange. The emerging markets have different traits or characteristics as compare to the developed markets. There is lack of evidence that whether the size and book-to-market equity affects the emerging markets or not.

In addition to the test the applicability of Fama \& French model, this research paper also counters the effects of the medium group firms in both SMB \& HML. As Fama \& French took two extremes for the formation of the factors (SMB \& HML) of their model. This can be over simplifying the returns or under simplifying the returns as not taking the effect of medium firms.

Javid and Ahmad (2009) stated that asset returns and macroeconomic events are, connected, as the marginal value of wealth that derives the asset market is also important for macroeconomic analysis. The main purpose behind this paper to address the Pakistani market and finds the applicability of fama and french model for the emerging market. As in Iqbal and Brooks (2007) stated that daily data provide more reliable and informative risk return relationship as compare to the monthly and weekly for both beta and for fama and french factors. Bundoo papers conducted on the Mauritius market and the main purpose was to find the effect of size and book to market equity for the emerging markets. Used an augmented Fama \& French model by incorporating time varying beta effect into it and found the significant importance for both the factors even after incorporating time varying beta.

How this paper differs with others and especially with those, which have been conducted on Pakistani market, will question the use of two extremes as other also followed the same methodology of Fama and French and some of them incorporating time varying beta to counter the effect of static risk.

The Fama and French took two extreme points to form the portfolios SMB (small minus big) and HML (high minus low), as risk is not static there number of numerous factors which effect the stock returns. We will take three points for both factors namely; small, medium and big for SMB and high, medium and low for HML. Homsud et al. (2009), will be using quantile regression as nature of data demands and in comparison to the OLS, quantile regression presents true results as methodology matters too. 
The plan for this study is as follows: section 1, introduction to the previous models and studies, section 2 reviews of previous empirical studies and findings for different markets. Theoretical framework for the study covered in section 3. Section 4 counters the methodology and data part, following with results in section 5 , section 6 consists of the comparative studies of models and the last section concludes the theory.

\section{Review of Previous Findings}

After going through different articles the synopsis can be; multifactor asset pricing model implies that the expected returns of assets are related to their sensitivity to change in the state of economy. There can be different variables, which can affect the stock returns, in this regard, Javid and Ahmad (2009) explains how the macroeconomic variables affect the stock returns over the time; found the source and the direction of the affects on the stock returns. Setting the criteria for the selection of the variables; selected the variables which are persistent to the investor and those which were extensively used in the research. It was revealed that macroeconomic variables affect the stock returns. Following the Iqbal and Brooks (2007) show that the Fama-French variables have some role in explain the return relationship in Pakistan market.

The most well known work in this regard is the series of papers by Fama \& French (1992, 1993, 1996 and 2004) forming portfolios of small minus big (SMB) and high minus low(HML) associated or calculated by firm size and book-to-equity ratio respectively. Shows how growth stock and value stock can affect the stock return. The success of fama and french model has directed a new debate in the finance literature over the interpretation of fama and french model and systematic risk. The reason behind the debate is; fama and french model factors provide returns on the portfolios which are formed on the basisof size and book-to-equity ratio. There is a clear lack of connection between economies to systematic risk. Xueping Wu (2005) cite that the world is dynamic and in this dynamic world the risk is always there along with the prices, risk with prices are likely to be varied through time and it depends on conditioning information. Testified the conditional regression model failed to explain the average returns even though conditioning the information. Using the conditional fama and french model; showed that conditioning the market wide information into can capture the return momentum. Results from the conditional regression in the instrument provide clear evidence that SMB and HML are time varying, where as reversal returns and momentum returns have different time varying characteristics. However, In and Kim (2007) determines the degree to which SMB and HML factors share information with the changes of state variables over various time scale, used the wavelet analysis for investigating the financial securities and found that $\mathrm{HML}$ is more closely related to future credit markets and interest rates with the market expectations. It has been questioned many times weather the fama and french model is efficient for the emerging markets or internationally, recently Homsud, et al. (2009) testified the efficiency of fama and french model for Thailand market, by adding SMB and HML factor of fama and french model into CAPM. This was done basically to find out can it improves the efficiency in predicting the risk and returns; and found that fama and french model explains risk and return better than CAPM. Answering the similar question, Al-Rjoub, et al. (2010) consider the four emerging markets like wise; Egypt, Jordan, Morocco \& Saudi Arabia. Price-earnings ratio, book-market ration, market capitalization and beta were used for the prediction of stocks return. Along with these entire estimators beta was found to be the better one, beta had a significant power for these four countries.

Several stock management companies prefer to form the investment portfolios under the factors of fama and french model likewise; Bickford discussed the importance of fama and french model and quoted several evidences in the support of the fama and french model. It also explained how value stocks can generate higher return than growth stocks and how small stocks can generate higher return than large stocks.

Technology can help the investor in earning the excess return, Cao, et al. (2005) found out ANN able to exploit the inefficiencies and custom to provide the investor with a technology so that one can earn excess return, in emerging market and it also offers the opportunity for the investor to improve his predicting power.

Iqbal and Brooks (2007) found that daily data provide more appropriate information regarding the risk return relationship in Pakistan market as compare to the weekly and monthly data. Ran the different beta estimators and also fama and french model and found that both beta and fama and french model factors explained the cross-sectional variation in the case of daily data. Ali, et al. (2003) paper shows that B/M effect is higher for stocks with higher idiosyncratic return volatility, higher transaction costs, and lower investor sophistication. Empirically examines different predictions of existing of B/M effect due volatility of arbitrage risk due to which arbitrage activity is discouraged. Also, discriminate the risk and mispricing. For arbitrageurs idiosyncratic volatility of the stocks is of more concern. If $\mathrm{B} / \mathrm{M}$ effect is cross-sectional correlated with arbitrage costs and investor sophistication measures, one can say that the $\mathrm{B} / \mathrm{M}$ effect is likely due to market mispricing. Moreover finds out the ability of $\mathrm{B} / \mathrm{M}$ ratio to predict future returns is greater for stocks with higher transaction costs and 
with less ownership by sophisticated investors. The results are consistent with the view that the BM effect is due to market mispricing. They found out the ability of $\mathrm{B} / \mathrm{M}$ to predict returns is most strongly and most consistently related to return volatility.

Different methodologies have different effect on the results despite the effect of variables like wise; Allen, et al. (2009) examined the behavior of three risk factors from fama-french model. The study shows that the traditional method of OLS becomes less effective when it comes to analyzing the extremes with in a distribution, which is often of key interest to investor and risk managers. OLS loses its effectiveness when we try to go beyond the median value or towards the extremes of data set. It has been proved that when it comes to extremes or boundaries values in distribution OLS method becomes inefficient. Quantile regression gives more efficient results when it comes to the boundary values of a distribution. When it comes to efficient risk assessment, it becomes important for an investor or risk manager $t$ to account for the extreme tails of a distribution. Fama \& French (1993) point out five common risk factors in returns on stocks and bonds, three of them are stock market factors: market risk, firm size and book-to-market equity. The other two factor are related bond market: maturity and default risks. In this paper Fama and French expanded their asset pricing test as in Fama and French (1992a): Expand the set of asset to explain returns, the only asset used before was common stocks. If markets are integrated, then a single model should explain bond returns. Variables are expanded too which used to explain returns. List of variables that are likely to explain bond returns; the motive behind this is to examine whether variables, which explain bond returns, help to explain stock returns Malin \& Veeraraghavan (2004) investigates the robustness of fama and french multifactor model for three European stock markets. Find out the small firm effect in Germany and France where as big Firm effect in UK. In this paper, methodology of fama and french (1993) is extended to the selected international markets. This paper also investigate the seasonal effects in the selected markets, empirical evidence suggests that small firms have larger risk. Shows that investor who invests in small stocks earns more who invest in large stock but for France and Germany. Shows there is growth effect for all three markets, finds that growth stocks generate higher returns than value stocks and challenged those papers who believe that high $\mathrm{B} / \mathrm{M}$ generate high returns as they are distressed.

Fama \& French (2004) main reason of attraction behind this model is, it suggests powerful pleasing predictions about how to measure risk and the relation $\mathrm{b} / \mathrm{w}$ expected return and risk. CAPM has never been a success. Whereas Black (1972) model which can accommodate a flatter tradeoff of average return for market beta has some success. The relation $\mathrm{b} / \mathrm{w}$ average return and beta is flatter than predicted by Sharpe-Lintner in CAPM. Bundoo investigated the validatiy of Fama and French for the Stock Exchange of Mauritius, the main purpose was to find the effect of size and book to market ratio effect and incorporate the time varying beta. It finds out that size and book to market factor do effects the Market of Mauritius. Geogory, et al. (2009) challanged the paper of Michou, Mouselli and Stark (2007) and Carhart (1997) momentum model. Both resulted that there is no SML and HML factors available in UK on timely basis and there is momentum factors for UK respectively. Along with that there was debate on the availability of data, so they also counter this problem to make free availability of data for academic research. Will be also be available in electronic format and will be updated every year.

Samer et al (2010) study examined the cross sectional behavior in unexplored emerging markets. The main purpose for paper was to quantify that beta has a significant power in all four markets (Egypt, Jordan, Morocco \& Saudi Arabia). To explain the nature of asset return, empirical evidence had been expanded. Found number of factors had effect on the asset return for these markets. Finally it was ended by predicting that beta has the significant power in explaining the asset return for all the four markets. This research also aligned with other papers who support the beta in explaining the stock returns. Dempsey (2009) the basic purpose or main finding of this research is whether Fama \& French model and MM approach can exist together. Whereas it should have noted, that Fama \& French model is algebraically inconsistent with MM approach. Specifically paper challenged on Lally's "leverage patch", they responded to this by presenting their approach to leverage, maintaining consistency between the FF model and MM propositions. Finally, this paper clarified it, that advantage conditions must apply to FF model so that it should have considered algebraically consistent with the rules of no arbitrage.

\section{Theoretical Framework}

Fama \& French, in their first paper in 1992 on fama and french three factor model, they hypothesized that market line should have been effected by more than one factor and they proposed three factors namely; first factor was same as in CAPM beta factor which measures the market risk of the stock, second factor counters for the size of the company, benchmarked the size of the company against the market value of the equity (MVE) as if small companies are riskier than the large companies then investor should accept higher rate of return while investing 
in the small companies and third factor is the book value of equity divide by the market value of equity or book to market value $(\mathrm{B} / \mathrm{M})$. If book value is larger than the market value than investor will be pessimistic about the stock and will expect the high rate of return against such investment (Eugene F. B., \& Michael, C. E.).

When Fama \& French tested their hypotheses, they didn't find any relation between beta and return where as they found small companies and companies with high $\mathrm{B} / \mathrm{M}$ ratio had higher return than the average stock.

Then in their second published study in 1993, Fama and French developed a three factor model; again the first factor in the model taken from CAPM; is the market risk premium, which is market return ('́m) minus risk free rate (rrff). For the formation of second factor they ranked all the traded stocks according to the size and then form two portfolios small and big. They didn't form any medium portfolio or more over didn't take the effect of medium portfolio. Then they calculated the average return of these two portfolios and in last they subtracted the return of the big portfolio from the return of small portfolio to form the new portfolio and they called this third portfolio SMB portfolio (small size minus big size). This third portfolio is designed in order to measure the variations, which are caused due to the size. to form the third factor they again ranked all the stocks but this time according to the book to market ratio. They placed 30 percent of stocks with the highest ratio into a portfolio they called the $\mathrm{H}$ portfolio for high $\mathrm{B} / \mathrm{M}$ ratios. The placed the 30 percent of stocks with lowest ratios into a portfolio called the $\mathrm{L}$ portfolio for low $\mathrm{B} / \mathrm{M}$ ratios. Then calculated the average return of $\mathrm{H}$ portfolio and for the $\mathrm{L}$ portfolio and they subtracted the return of low ratio portfolio from the high ratio portfolio and they called the resulted portfolio the HML portfolio. (Eugene F. Brigham and Michael C. Ehrhardt) (Note 4).

This research paper questions the construction of the Fama \& French model. As they took two extremes; whereas will take three points both in size factor and book to market factor to form the four additional factors and will compare the effect of CAPM, Traditional Fama \& French and Modified Fama \& French.

\subsection{Hypothesis}

- Fama and French model accounts the difference between a portfolio of small firms and a portfolio of large firms, which can be over simplified or under simplified.

- Differences between a portfolio of small firms and a portfolio of medium firms have some significant importance in the market.

- Questioning the extreme points by taking in account the medium point for both factors (SMB and HML).

- To test the relation of SM (small minus medium) with dependent variable; required rate of return.

- To see whether MB (medium minus big/large) does have effect required rate of return.

- To counter, the impact of HM (high minus medium) on required rate of return.

- To spot, the relation between ML (medium minus low) and required rate of return.

- To figure out, the degree of affection of new variables on required rate of return.

To find out does medium points really have any effect while constructing the portfolios and in addition to this also to find the relation of new factors with required rate of return. Redundant variable test uses to find the out the relation between dependent variable and independent variable; degree or strength of relation can be found out through the percentage of probability. Will use the limitation by equalizing the $\beta=1$ or null hypothesis to one; keeping the market risk and security risk equal, or otherwise considering that market risk and security risk has the co-movement. Which can be proofed if hypothesis will accept and if hypothesis is rejected then there will not be any relation between dependent and independent variable.

\section{Methodology}

Different author used different models in calculation of the fama and french model and sometimes with the addition of other factors likewise, Bundoo the purpose for his paper was to find out the empirical evidence whether the size and book-to-market equity affects emerging markets or not. Used GARCH $(1,1)$ to calculate the conditional market volatility, he used Schwert \& Seguin (1990) model which estimates the single factor model portfolio return which incorporate the estimation of time varying beta and the augmentation of Fama $\&$ French model by incorporating the time variation of beta and sum up his result; fama and french model can be held for Stock Exchange of Mauritius. More over both size and book-to-market factor of fama and french models are present in Stock Exchange of Mauritius. He also incorporated the concept of time varying beta and found that even in the presence of time varying beta, size effect and book-to-market equity effects are still important. Iqbal $\&$ brooks (2006) used OLS model to calculate the betas from excess return model and used EGARCH to measure the unsystematic risk. 
Allen et al. (2009) observed the behavior of three risk factors form Fama \& French model. The study evidenced, OLS method become less effective when it comes to calculate the extremes with in distribution which is often of key interest to investor and risk managers. OLS loses its effectiveness when we try to go beyond the median value or towards the extremes of data set. As OLS assume that variance has to be remain constant or homoscedastic.

Analyzing the conditional mean of dependent variable number odf regression models are concerned, now day's interest in methods of modeling other aspects of conditional distribution is increasing. One of the regression approaches which getting great interest of researcher is quantile regression, quantile regression, models the quantiles of the dependent variable given a set of conditioning variables.

As initially proposed by Koenker and Bassett (1978), the relationship between regressors and a specified quantile of the dependent variable can be estimated by quantile regression. Least absolute deviations (LAD) estimator is one of the important cases of quantile regression, which corresponds to fitting the conditional median of the response variable.

Quantile regression portray a complete picture of the conditional distribution than the conditional mean analysis alone, allowing us, for example, to depict how the median, or possibly the 10th or 95th percentile of the response variable, are affected by regressor variables. Moreover, since the quantile regression approach does not require strong distributional assumptions, it offers a distributionally robust method of modeling these relationships. Whereas OLS need strong assumptions to back its usage which in result can change effect of the whole data?

So, after going through different articles and readings; preferably using quantile regression for perspective model. Quantile regression becomes more effective tool as in comparison to OLS, when it comes to analyze the extremes of distribution.

In this research return of portfolio and return of market is calculated through the use of logarithmic term:

$$
\mathrm{R}=\ln (\mathrm{P} \quad / \mathrm{P} \quad-1)
$$

It can be witnessed in Homsud et al. (2009) as they examined the validity of Fama \& French model on Thailand market, and used the logarithmic formula for the calculation of market and portfolio return.

For instance, the measurement scope as 1 month; returns can be measured from the end price of the preceding month (can be denoted as $t-1$ ) to the ending price of current month. This calculates the arithmetic or discrete rate of return. This will explains the simple return, which over the time have the discrete impact over the time, which leads to time inconsistent values. Where as to explain the concept or return one should have to obtain the time consistent values which can be obtained by the logarithmic formula

$$
\mathrm{R}=\ln (\mathrm{P} / \mathrm{P}-1) \text { (Philip Jorion) }
$$

\subsection{Data}

Companies selected for this research are those who have been listed on Karachi Stock Exchange from January 01 2005-December 31 2009. That was 473 companies in number which were listed in this period (2005-2009), but in last only 340 companies were selected for the research as there was no data found for remaining companies (133 companies out of 473). Daily share price was taken for these companies for 5 years (2005-2009). Use business recorder as source of collecting share prices. This research counters the effect of medium portfolio too (both in SML and HML).

\subsubsection{Small Minus Big, Small Miuns Medium and Medium Minus Large}

Selected companies (340) were arranged in the descending order as per according to their total asset respectively for each year from 2005-2009 $(2005,2006,2007,2008$ \& 2009). Balance sheet analysis which was obtained from State Bank of Pakistan was used for asset values.

First five companies with smaller amount of asset as compare to others are selected as small capitalized firms to form small company group; similarly the last five companies with larger amount of asset as compare to other are selected as large capitalized firms to form big company group.

Medium companies are selected on the basis of percentile; a company with $50^{\text {th }}$ percentile was taken as cut off point and then two companies below to $50^{\text {th }}$ percentile company and two above to $50^{\text {th }}$ percentile company including this $\left(50^{\text {th }}\right.$ percentile) company were selected to form medium company group.

After forming the group for each small, medium and big, then share prices on monthly (ending value for every month) basis were used to calculate average return for each. 
Then average return of medium group companies were subtracted from average return of small group companies to form SM similarly average return of big group companies were subtracted from average return of medium group companies to form MB and the average return of big or large group of companies were subtracted from the average return of small group of companies to form SMB. Same procedure was, followed for each year.

According to efficient market theory; companies with small capitalization have high risk for investor so these companies need to give high rate of return to attract the investors and firms with large or big capitalization value mean have low risk for investors.

\subsubsection{High Minus Low, High Minus Medium and Medium Minus Low}

Same as in SMB, the selected companies were arranged in the descending order to their book/market ratio for each year from 2005-2009 (2005, 2006, 2007, 2008 \& 2009). Book value was calculated dividing equity by number of shares for each company and then dividing the obtained value by market price which was obtained from business recorder. Values for equity and number shares were again obtained from Balance Sheet analysis. Companies with negative book to market value were dropped whiling forming the groups.

First five companies with smaller value of book to market were selected to form the high group of firms, similarly last five companies with larger values of book to market were selected to form low group of firms.

Similarly in SMB, percentile is used to form cut off point. The company with $50^{\text {th }}$ percentile was taken as a cutoff point and two companies above the $50^{\text {th }}$ percentile company and two companies below the $50^{\text {th }}$ percentile company and including $50^{\text {th }}$ percentile company will be selected to form the medium group firms.

After forming the groups, monthly share prices (prices at the end of each month) were used to calculate the average return for each group.

Average return of medium group companies were subtracted from the average rerun of high group companies to form HM, similarly average return of low companies were subtracted from the average return of medium group companies to form ML and then low average return of low group companies were subtracted from the average return of high group companies to form the HML.

According to the efficient market theory, companies with higher book to market value has to offer higher rate of return to investor, as there is more risk for investor to invest in such company whose book value is higher than the market value.

\subsubsection{Risk Free Rate and Market Risk Premium}

Risk free rate (Rf) a rate which is free of risk or only incorporates the default risk. A rate which is given against government securities normally or against the risk free securities. This is the minimum rate which an investor can expect from the investment. Normally it is also known as t-bill rates.

In this research 3 months t-bill rates are taken as risk free rate; took the average for each quarter and then divide it by the square root of 3 as to convert it to monthly rate. (Philip Jorion. VaR Methods).

The 3 months bid rates for the calculation o f risk free rate was taken from the site of State Bank of Pakistan.

Market risk (Rm); was calculate by the help of the logarithmic formula:

$$
R=\ln \left(\begin{array}{lll}
P & / P & -1
\end{array}\right)
$$

Closing prices for index were used to calculate the $\mathrm{Rm}$ and the index prices were taken from the yahoo finance.

\subsection{Variables}

Following are the variables, which effect the selection of companies' during the procedure:

\section{- KSE Index}

Selected those companies which are listed in Karachi stock Exchange for 5 years from 2005-2009. Total of 473 companies where found to be traded for 5 years on Karachi stock Exchange companies but In last only 340 companies were selected due to non availability of data of remaining 133 companies.

\section{- No. of shares}

Number of shares effects in the arrangement of the companies while forming the HML, HM and ML factors. As number of shares use to calculate the book to market ratio.

\section{- Equity}

Equity also use in the calculation of book value, as the formula for it is Book Value= Equity / No. of shares. 
Higher the book value higher the return one should expect. Higher the equity higher the book to market ratio, similarly lower the no. of shares higher the book to market value for the perspective firm. Book value is one of the main elements which is used to calculate the book to market ration.

\section{- Market Value of all shares}

Market value is second element, which use to calculate the book to market ratio;

Book to market $=$ Book value $/$ Share price

Higher the share price lower the book to market ratio, higher the book value higher the book to market ration which is an alarming sign for any investor and one should expect higher rate of return against his or her investment.

\section{- Share price at the end of Dec}

Took the share price for each year at the end of the December. Which has significant impact over the book to market ratio.

\section{- $\quad$ B/M ratio}

Book to market ration, use to form the high minus low, high minus medium and medium minus low portfolios. Arranged the companies according to descending order of the book to market value. so $1^{\text {st }}$ five companies with lowest book to market ratio selected to form low group, similarly the last five companies with high book to market ratio were selected for high group of companies. So book to market ratio as a great importance for this model.

\section{- $\quad$ Assets}

Total value of assets for each selected company were used for each year to arrange the company in the descending order to form Small minus Big, Medium minus Big and Small minus Medium portfolios. Top $1^{\text {st }}$ five companies with the lowest asset values were selected to form small group of companies, similarly last five companies with highest asset values were selected to form high group of companies.

Asset value, equity amount and number of shares have taken from the Balance Sheet Analysis of State Bank of Pakistan and share prices have taken from the business recorder.

\subsection{Equations}

\section{- CAPM}

First ever model introduced to measure the risk and return relationship, and to help managers and investor to form the efficient portfolio. It is also known as single factor model too; according to this model there is only one factor that is market risk.

$$
R R R=R f+(R m-R f) \beta+\mu
$$

$R R R$ is the required rate of return for an individual.

$\mathrm{Rf}$ is the risk free rate which is usually equals to the t-bill rate.

$\mathrm{Rm}-\mathrm{Rf}$ is the market risk premium.

B beta is the measurement of individual security to a well-diversified portfolio.

$\mu$ is the error term.

\section{- Traditional Fama And Frecnh}

After several years researcher started questioning about the validity of CAPM and they proposed there must be some more factors, there are some more factors, which are associated with risk. And then in 1992 Fama and French proposed a multifactor model, in which they incorporate the microeconomic variable into it.

$$
R i-R f=(R m-R f) \beta^{1}+(S M B) \beta^{2}+(H M L) \beta^{3}+\mu
$$

$\mathrm{Ri}$ is portfolio's return rate.

$\mathrm{Rf}$ is the risk free rate.

$\mathrm{Rm}$ is return for the whole stock market.

SMB is size factor Small cap minus Large cap.

HML is book to market ration factor High portfolio minus Low portfolio. 


\section{- Modified Fama And French}

As the traditional model just added new factor into it that covers the impact of medium portfolio as in traditional Fama and French extreme points were captures for the formation of the portfolios.

$$
R i-R f=\beta+(R m-R f) \beta^{1}+(S M B) \beta^{2}+(S M) \beta^{3}+(M B) \beta^{e}+(H M L) \beta+(H M) \beta+(M L) \beta+\mu
$$

Ri portfolio's return.

$\mathrm{Rf}$ risk free rate.

$\mathrm{Rm}$ return for the stock market.

SMB size factor small minus big.

SM new size factor Small minus Medium.

MB new size factor Medium minus Big.

HML Book to market factor high minus low.

HM new book to market factor High minus Medium.

ML new book to market factor Medium minus Low.

\section{Results}

Model estimation to find the validity of modified Fama and French in comparison with the CAPM and traditional Fama and French.

\subsection{CAPM: Estimated}

Table 1. CAPM

\begin{tabular}{|c|c|c|c|c|}
\hline \multicolumn{5}{|c|}{ Dependent Variable: (Ri - Rf) } \\
\hline \multicolumn{5}{|c|}{ Method: Quantile Regression (Median) } \\
\hline \multicolumn{5}{|c|}{ Date: 05/09/11 Time: 01:31 } \\
\hline \multicolumn{5}{|c|}{ Sample: 2005M02 2009M12 } \\
\hline \multicolumn{5}{|c|}{ Included observations: 59} \\
\hline \multicolumn{5}{|c|}{ Huber Sandwich Standard Errors \& Covariance } \\
\hline \multicolumn{5}{|c|}{ Sparsity method: Kernel (Epanechnikov) using residuals } \\
\hline \multicolumn{5}{|c|}{ Bandwidth method: Hall-Sheather, bw $=0.24957$} \\
\hline \multicolumn{5}{|c|}{ Estimation successfully identifies unique optimal solution } \\
\hline Variable & Coefficient & Std. Error & t-Statistic & Prob. \\
\hline $\mathrm{C}$ & 0.000000 & 0.025913 & 0.000000 & 1.0000 \\
\hline$(\mathrm{Rm}-\mathrm{Rf})$ & 1.140124 & 0.075346 & 15.13193 & 0.0000 \\
\hline Pseudo R-squared & 0.597922 & & & \\
\hline AdjustedR-squared & 0.590868 & & & \\
\hline
\end{tabular}

The estimation of CAPM shows, Rm-Rf t-statistic value is greater than 2 which show that it has a significant impact on the dependent variable RRR. In addition to that it has a positive relation with RRR, as coefficient of $\mathrm{Rm}$-Rf 1.14 has a positive value. Positive relation means RRR will increase as $\mathrm{Rm}$-Rf increase i.e. RRR will increase by 1.14 due to change in Rm-Rf by 1 . Pseudo R-squared .5979, which explains the variation in dependent variable due to the independent variable or in other words this model explains the $59.79 \%$ variation. 


\subsection{Traditional Fama \& French}

Table 2. Traditional Fama \& French

\begin{tabular}{|c|c|c|c|c|}
\hline \multicolumn{5}{|c|}{ Dependent Variable: (Ri - Rf) } \\
\hline \multicolumn{5}{|c|}{ Method: Quantile Regression (Median) } \\
\hline \multicolumn{5}{|c|}{ Date: 05/09/11 Time: $01: 30$} \\
\hline \multicolumn{5}{|c|}{ Sample: 2005M02 2009M12 } \\
\hline \multicolumn{5}{|c|}{ Included observations: 59} \\
\hline \multicolumn{5}{|c|}{ Huber Sandwich Standard Errors \& Covariance } \\
\hline \multicolumn{5}{|c|}{ Sparsity method: Kernel (Epanechnikov) using residuals } \\
\hline \multicolumn{5}{|c|}{ Bandwidth method: Hall-Sheather, $b w=0.24957$} \\
\hline \multicolumn{5}{|c|}{ Estimation successfully identifies unique optimal solution } \\
\hline$\underline{\text { Variable }}$ & Coefficient & Std. Error & $\mathrm{t}$-Statistic & Prob. \\
\hline $\mathrm{C}$ & -0.015716 & 0.027195 & -0.577904 & 0.5657 \\
\hline$(\mathrm{Rm}-\mathrm{Rf})$ & 1.035353 & 0.089241 & 11.60178 & 0.0000 \\
\hline HML & 0.126683 & 0.080981 & 1.564352 & 0.1235 \\
\hline SMB & 0.032673 & 0.119684 & 0.272997 & 0.7859 \\
\hline Pseudo R-squared & 0.615571 & & & \\
\hline Adjusted R-squared & 0.594602 & & & \\
\hline
\end{tabular}

Table 2 account to the traditional Fama \& French model; which witnessed that only variable which has the significant impact on the RRR is Rm-Rf. As its t-statistic value is greater than 2 which mean it impacts the RRR significantly and also having the positive relation. HML \& SMB do not have the significant impact as evident through $t$ values. Plus these also have positive relation, by positive relation means RRR will increase 1.56 as HML increase by 1 or more over RRR will change by 1.56 due to change in HML of 1 . Pseudo R-squared 61.56\% and Adjusted R-squared $59.46 \%$ explains the proportion of variation in dependent variable due to the independent variables. In other words this much percentage of variation is explained by model.

\subsection{Modified Fama \& French}

Table 3. Modified Fama \& French

\begin{tabular}{|c|c|c|c|c|}
\hline \multicolumn{5}{|c|}{ Dependent Variable: (Ri - Rf) } \\
\hline \multicolumn{5}{|c|}{ Method: Quantile Regression (Median) } \\
\hline \multicolumn{5}{|c|}{ Date: $05 / 09 / 11$ Time: $01: 26$} \\
\hline \multicolumn{5}{|c|}{ Sample: 2005M02 2009M12 } \\
\hline \multicolumn{5}{|c|}{ Included observations: 59} \\
\hline \multicolumn{5}{|c|}{ Huber Sandwich Standard Errors \& Covariance } \\
\hline \multicolumn{5}{|c|}{ Sparsity method: Kernel (Epanechnikov) using residuals } \\
\hline \multicolumn{5}{|c|}{ Bandwidth method: Hall-Sheather, bw $=0.24957$} \\
\hline \multicolumn{5}{|c|}{ Estimation successfully identifies unique optimal solution } \\
\hline Variable & Coefficient & Std. Error & t-Statistic & Prob. \\
\hline $\mathrm{C}$ & -0.012532 & 0.020874 & -0.600355 & 0.5509 \\
\hline$(\mathrm{Rm}-\mathrm{Rf})$ & 1.043841 & 0.064778 & 16.11416 & 0.0000 \\
\hline HM & 0.286450 & 0.258661 & 1.107431 & 0.2733 \\
\hline HML & -0.298433 & 0.251138 & -1.188327 & 0.2402 \\
\hline MB & -0.312433 & 0.163149 & -1.915019 & 0.0611 \\
\hline ML & 0.448927 & 0.326052 & 1.376855 & 0.1746 \\
\hline SM & 0.422692 & 0.206058 & 2.051329 & 0.0454 \\
\hline SMB & -0.047837 & 0.171588 & -0.278788 & 0.7815 \\
\hline Pseudo R-squared & 0.672967 & & & \\
\hline Adjusted R-squared & 0.628081 & & & \\
\hline
\end{tabular}

Table 3 address the test of significance of the variables for the New or Modified Fama \& French model and which finds out that $R m-R f$ has the significant impact on the dependent variable RRR (Ri-Rf) as its t-statistic 
value is above 2 which means its impact is highly significant. SM (Small minus Medium) also has the significant impact on RRR as its t-statistic value is also above 2. However both the variables has the positive relation with RRR, as RRR will increase by 2.05 as SM will increase by 1. Other than these 2 variables, HM (High minus Medium), HML (High minus Low), MB (Medium minus Big), ML (Medium minus Low) and SMB (Small minus Big) do not have the significant impact on the RRR and some of these variables have inverse relation i.e. RRR will decrease by 2984 as HML will increase by 1 or RRR will change by .2984 as due to change in HML of 1. Pseudo R-squared 0.673 and Adjusted R square is 0.6281 which explains that the proportion of the variation in the dependent variable due to the independent variables i.e. prescriptive dependent variable accounted for by the explanatory variables. In other words $62.81 \%$ variation is explained by this model.

Pseudo R-squared value has proven modified Fama and French more valid as compare to traditional Fama and French and CAPM. Which also means that new factors into model counters the risk more effectively and presents the true picture. It provides evidence that medium point does have effect for Pakistani market, so for the portfolio construction or portfolio analysis one should need to consider the effect of medium point or medium factors. By taking extreme positions, it does not provide the true picture. It can under simplify the results or may over simplify too.

\subsection{Requried Rate of Return}

Table 4. RRR on annual basis

\begin{tabular}{llll}
\hline Annual(RRR)_Trad & Annual(RRR)_CAPM & Annual(RRR)_N & Year \\
\hline$-2.42 \%$ & $-2.26 \%$ & $-2.57 \%$ & 2005 \\
$-0.50 \%$ & $-3.09 \%$ & $3.52 \%$ & 2006 \\
$2.37 \%$ & $0.86 \%$ & $1.67 \%$ & 2007 \\
$-14.16 \%$ & $-17.59 \%$ & $-13.50 \%$ & 2008 \\
$13.32 \%$ & $11.48 \%$ & $13.90 \%$ & 2009 \\
\hline
\end{tabular}

In Pakistan there number of risk factors, which need to be consider while investing as per the conditions of Pakistan demand. One should expect high rate of return against his investment. Negative rate of return means investor will not be even getting the actual amount back. Table 2, portraying the required rate of return on annual basis for Pakistani market. As evident in model estimation, pseudo R square presenting the facts that modified fama and french model has higher rate for explain the variation; higher the pseudo $\mathrm{R}$ square value higher the explain power of perspective model. Modified FF outperformed each in comparison to traditional FF and CAPM except 2007. For the most recent year 2009 it is $13.9 \%$ and it is actual rate of return not the expected one.

\section{Comparative Studies of Models}

Risk measurement against the investor investment has always been of great question that amount of return one should get for his investment. Many models had been, proposed to answer such question one of the basic and well know model is CAPM but after its emergence, it always remain in debate whether a a return needs to be measured against only for market risk or other factors should also need to be take apart of it. For the case of Pakistan won't find great number of studies; Javed \& Brooks (2007) who found Fama \& French model do have some role to explain the return relationship for the Pakistani market. They found daliy data to more support as compare to weekly and monthly to explain the return relationship and debated that Fama \& French size (SMB) and book to market (HML) were found to be relevant for Pakistani market. Javid \& Ahmad (2009) found the return relationship through the conditional CAPM additional to some macroeconomic variable and their result proposed that some of these macro variables do help in explaining the return for Pakistan.

\subsection{Redundant Variable Test}

As new variables have been, add in modified Fama \& French to check the applicability of fama and french model for Pakistani market in addition to some new factors. Usually Wald test or redundant variable test conducts to check the degree of relation among the variables. 


\subsubsection{CAPM}

Table 5. Wald test for CAPM

\begin{tabular}{llll}
\hline Test Statistic & Value & df & Probability \\
\hline $\mathbf{( R m - R f )}$ & & & \\
t-statistic & 1.859754 & 57 & 0.0681 \\
\hline
\end{tabular}

Table 5 witnessing the result for the significance of Rm-Rf to RRR as probability value is above $5 \%$ which showing that $\mathrm{Rm}$-Rf has the significant impact and proving that null hypothesis has been, accepted. Along with it individual companies risk premium and market risk premium are same or market risk and security risk are same. As coefficient sign it has the positive relation with required rate of return which means, it will move along with RRR i.e. required rate of return will increase by 1.14 times due to change of $1 \mathrm{in} R \mathrm{~m}-\mathrm{Rf}$ or in market risk premium.

\subsubsection{Traditional Fama and French}

Table 6, portraying the clear picture for the relationship of variables with required rate of return to explain the return, for traditional Fama \& French model. Probability value for intercept is above 5\%, which is pretty convincing that null hypothesis has been accepted. It means it has the significant impact on required rate of return, as it has the inverse relation with required rate of return as coefficient of intercept or constant has the negative value. Inverse relationship means, RRR will decrease by .015 due to increase in intercept by 1 . Similarly probability value for Rm-Rf showing that null hypothesis for this is also accepted and also it has significant impact over the required rate of return. As per the coefficient value required rate of return and market risk premium has the positive relation. There exist a positive relation among RRR \& Rm-Rf, so there is co-movement between both these; beta measures the contribution of an asset to the variability of the market index portfolio and the hypothesis is that in case asset has the same level of risk as the market index than beta would be one; which approach that market risk and security risk are same. As Rm-Rf \& RRR has positive relation, so RRR will increase by 1.03 due to increase of $1 \mathrm{in} \mathrm{Rm-Rf.} \mathrm{In} \mathrm{case} \mathrm{of} \mathrm{HML} \mathrm{probability} \mathrm{is} \mathrm{zero} \mathrm{which}$ means null hypothesis is rejected and it have no the significant impact on required rate of return or in explaining the return relationship for Pakistani market in required rate of return, so it will not be having any significant impact on required rate of return. In this case there is no co-movement between required rate of return and HML, so there is no relation between market risk and the security risk. Likewise, SMB also have no relation with the dependent variable RRR, as probability value for SMB is zero which means it has insignificant impact on required rate of return.

Table 6. Wald test for Traditional FF

\begin{tabular}{llll}
\hline Test Statistic & Value & Df & Probability \\
\hline C t-statistic & -0.577904 & 55 & 0.5657 \\
(Rm-Rf) t-statistic & 0.396148 & 55 & 0.6935 \\
HML t-statistic & -10.78423 & 55 & 0.0000 \\
SMB t-statistic & -8.082347 & 55 & 0.0000 \\
\hline
\end{tabular}

\subsubsection{Modified Fama \& French}

Table 6.3, presenting the results for modified Fama \& French, the proposed model in which new variables has been added, probability value for intercept is above $5 \%$, so null hypothesis is accepted which leads to the significance of intercept on required rate of return, as coefficient of intercept has the negative value so it has inverse relation with required rate of return i.e. required rate of return will increase by .0125 due to increase of 1 in intercept or constant. Market risk premium also has the significant impact over the RRR as probability value for RM-Rf is above $5 \%$, so null hypothesis accepted and the coefficient value of Rm-Rf positive too, which approaches that required rate of return and market risk premium has positive relation and have the co movement behavior, which means individual company risk premium and market risk premium are same. As there is positive relation between RRR and Rm-Rf so, RRR will decrease by 1.043 due to change of 1 in market risk premium. In explain the relation between HM \& required rate of return, probability has value a less than $1 \%$, so HM has insignificant impact on required rate of return. Similarly, HML has zero probability, which means it has 
no significant impact on dependent variable (required rate of return). MB also has the zero probability so it also be having the same impact on required rate of return. Probability value for ML is higher greater than $5 \%$ so it has a significant impact on the required rate of return, as its probability value is above $5 \%$ so hypothesis is accepted; RRR will increase by 0.44 due to increase of 1 in ML. probability for SM is less than $1 \%$ so it has insignificant impact on dependent variable so do null hypothesis rejected too and for SMB has the similar result as its value for probability is zero too which means null hypothesis is rejected and it has insignificant impact on th required rate of return.

Table 7. Wald test for modified FF

\begin{tabular}{llcc}
\hline Test Statistic & Value & Df & Probability \\
\hline C t-statistic & -0.600355 & 51 & 0.5509 \\
(Rm-Rf) t-statistic & 0.676783 & 51 & 0.5016 \\
HM t-statistic & -2.758626 & 51 & 0.0080 \\
HML t-statistic & -5.170208 & 51 & 0.0000 \\
MB t-statistic & -8.044392 & 51 & 0.0000 \\
ML t-statistic & -1.690137 & 51 & 0.0971 \\
SM t-statisti & -2.801677 & 51 & 0.0072 \\
SMB t-statistic & -6.106690 & 51 & 0.0000 \\
\hline
\end{tabular}

The main purpose for applying this statistical test is to find the validity of these model specially for modified Fama \& French; to check the validity for model the value of intercept needs to be zero i.e. $\beta=0$, with the probability of $55.09 \%$ and probability of $56.57 \%$ it has been proofed that Modified Fama \& French and Traditional Fama \& French have the validity respectively.

\section{Conclusion}

The traditional Fama \& French model took two extremes and found the size and book to market effect, so do other, other followed the same criteria to testify the validity of Fama \& French for different markets some used time varying beta effect and some of them compared the Fama and French model with CAPM to explain the risk return relationship for perspective market. Taking two extreme points for forming the portfolios to find out required rate for may not give the true result, either it can over simplify or under simplify. As risk can never be a static, it's a dynamic concept. Iqbal and Brooks (2007) conducted the research on Pakistani market to find the relationship of risk and return, and to find the effect of size and book to market factors. Compares beta and Fama \& French factors which one of them lead to the relation of risk and return. Concluded that size and book to market effects do exist in Pakistani market and beta explain the cross sectional variation didn't find positive relationship between risk and return, but addition to it the nature of data was daily, presented that daily data is more viable in explaining the risk return relationship. Followed the same procedure; as in Fama Frecnh 1993 for the construction of portfolios.

Use of methodology also have significant effect; for the nature of data for this paper it is recommended to use quantile regression; in Allen et al. (2009) debated clearly the affection of qualtile regression for this data natrue, as OLS has its own limitation one should need to follow the number assumption which can affect the data on huge scale and in this way we may not get the true result. Paper showed that OLS become less effective when it is question of measuring the extremes in the distribution, which is concerned to the managers or investors. OLS loses its effectiveness when one try to go beyond the median value or towards the extremes of the data. When it comes to the efficient risk management, it also becomes important for the manger and the investor to counter for the extreme points of data set.

Results clearly witness it that Modified Fama, French has outperformed the Traditional Fama and Frecnh, and Capital Asset Pricing Model, one there need to be more than one factor to explain the risk return relationship, and efficient risk management cannot be, done through only considering the single beta. For this purpose the need for new model has been identified and it was proposed back in 1992, but they took extreme positions for the construction of factors for the model which can over simplify or under simplify the risk return relationship. So new factors are, added to the Traditional Fama and French Model to answer the question of whether there is any effect by adding medium portfolios into the existing factors. Result clearly concluded that there exists the effect of medium portfolios into the present factors, as Modified Fama and French clearly outperforms the 
Traditional Fama and Frecnh and Capital Asset Pricing Model. For effective risk management and for effective formation of portfolio one should need to consider the effect of medium points so get the true return.

As it has been, proven that medium, effect does exist in the case of Pakistani market and Modified Fama and French is applicable for the Pakistani market.

There can be possibilities that medium effect do exist in other emerging or third world markets or may be in developed countries too.

\section{References}

Ali, A., Lee-Seok, H., \& Mark, A. T. (2003). Arbitrage risk and the book-to-market anomaly. Journal of Financial Economics, 69, 355-373. http://dx.doi.org/10.1016/S0304-405X(03)00116-8

Allen, D. E., Abhay, K. S., \& Robert, P. (2009). Asset pricing, the FF factor model, and the Implications of quintile regression analysis, School of Accounting. Finance and Economics, Edith Cowan Universty, Working paper 0911, Bickford, Joel.D, Fama/French Three Factor Model. Bickford Investment Management Services.

Al-Rjoub, Samer, A. M., Abdullah, Al. Y., \& Izz, E. N. A. (2010). Beta Wins Again: Case of four Emerging Markets. Journal of Economic Cooperation and Development, 31, 1-16.

Cao, Q., Karyl, B. L., \& Marc, J. S. (2005). A comparison between Fama and French's model and artificial neutral networks in predicting the Chinese stock market. Computers \& Operations Research, 32, 2499-2512. http://dx.doi.org/10.1016/j.cor.2004.03.015

Dempsey, M. (2009). The Famaand French three-factor model and leverage: compatibility with the Modigliani and Miller propositions. Investment Management and Financial Innovations, 6(1).

Fama, E. F., \& French, K. R. (1992). The Cross Section of Expected Stock Returns. Journal of Finance, 47, 427-465. http://dx.doi.org/10.1111/j.1540-6261.1992.tb04398.x

Fama, E. F., \& French, K. R. (1993). Common risk factors in the returns on stocks and bonds. Journal of Financial Economics, 33, 3-56. http://dx.doi.org/10.1016/0304-405X(93)90023-5

Fama, E. F., \& French, K. R. (1998). Value versus growth: the international evidence. Journal of Finance, 53, 1975-1979. http://dx.doi.org/10.1111/0022-1082.00080

Fama, E. F., \& Kenneth, R. F. (1993). Common risk factors in the returns on stocks and bonds. Journal of Financial of Economics, 33, 3-56. http://dx.doi.org/10.1016/0304-405X(93)90023-5

Fama, E. F., \& Kenneth, R. F. (1996). Multifactor Explanation of Asset Pricing Anomalies. Journal of Finance, 51, 55-87. http://dx.doi.org/10.1111/j.1540-6261.1996.tb05202.x

Fama, E. F., \& Kenneth, R. F. (2004). The Capital Asset Pricing Model: Theory and Evidence. Journal of Economics Perspectives, 18(3), 25-46. http://dx.doi.org/10.1257/0895330042162430

Fuller, K. P., Bonnie, F., \& Robert, A. V. N. (2009). Is Information Risked Price. School of Business Administration, University of Mississippi.

Geogory, A., Rajesh, T., \& Angela, H. (2009). The Fama French and Momentum Portfolios and factors in the $U K$. Xfi Center for Finance and Investment, University of Exeter.

Homsud, N., Jatuphon, W., Sirina, P., \& Jitwatthana, J. (2009). A study of FF model and CAPM in the stock Exchange of Thailand. International Research Journal of Finance and Economics.

In, F., \& Sangbae, K. (2007). A note on the relationship between Fama-French risk factors and innovations of ICAPM state variables. Finance Research Letters, 4, 165-171. http://dx.doi.org/10.1016/j.frl.2007.04.001

Iqbal, J., \& Robert, B. (2007). Alternative beta risk estimators and asset pricing tests in emerging markets: The case of Pakistan. Journal of Multinational Financial Management, 17, 75-93. http://dx.doi.org/10.1016/j.mulfin.2006.04.001

Javid, A. Y., \& Eatzaz, A. (2009). Testing Multifactor Asset Pricing Model in Case of Pakistan Market. Journal of Finance and Economics, 25, 1450-2887.

Kothari, S. P., Shanken, J., \& Sloan, R. G. (1995). Another look at the cross-section of expected returns. Journal of Finance, 50, 185-224. http://dx.doi.org/10.1111/j.1540-6261.1995.tb05171.x

Malin, M., \& Madhu, V. (2004). On the robustness of the fama and french multifactor model: evidence from France, Germany and the UK. International Journal of Business and Economic, 3(2), 155-176. 
Ro, S., \& Alan, J. Z. (2009). Does Focus Really Matter? Specialized vs Diversified REITs. Journal of Real Estate Financial Economics.

Wu, X. P. (2002). A conditional multifactor analysis of return momentum. Journal of Banking \& Finance, 26, 1675-1696. http://dx.doi.org/10.1016/S0378-4266(01)00179-0

\section{Notes}

Note 1. http://www.moneychimp.com/articles/risk/multifactor.htm

Note 2. http://www.investopedia.com/terms/s/small_minus_big.asp

Note 3. http://www.investopedia.com/terms/h/high_minus_low.asp

Note 4. Financial Management 11th Edition

\section{Copyrights}

Copyright for this article is retained by the author(s), with first publication rights granted to the journal.

This is an open-access article distributed under the terms and conditions of the Creative Commons Attribution license (http://creativecommons.org/licenses/by/3.0/). 